\title{
Labores, quitutes e panelas: em busca do lar ideal ${ }^{*}$
}

\author{
Maria Cecília Barreto Amorim Pilla**
}

\begin{abstract}
Resumo
A partir do conceito de auto-governo, entendido como um modelo psicológico capaz de garantir o reconhecimento e respeito do próximo, uma valorização de si mesmo, este artigo propõe uma reflexão a respeito da mulher no desempenho do papel de "rainha do lar" no Brasil do início do século XX. Na preparação da casa repousava a valorização de uma conduta controlada da dona-de-casa, que deveria manter o controle sobre tudo e sobre todos, tendo aí a oportunidade de demonstrar sua capacidade de governar a si, seu lar e sua família.
\end{abstract}

Palavras-chave: Contenção, Auto-governo, Administração do Lar.

\footnotetext{
* Recebido para publicação em março de 2006, aceito em janeiro de 2007.

** Professora de História Moderna e Contemporânea nos cursos de Filosofia e Teologia da PUC-PR. ceciliapilla@yahoo.com.br
}

cadernos pagu (30), janeiro-junho de 2008:329-343. 
Labores, quitutes e panelas

Handiwork, Dainties and Pans:

Searching for the Ideal Home

\begin{abstract}
This study begins from the concept of self-guidance understood as a psychological model capable to guarantee the recognition and respect of the next one, a self-valorization. It propitiates a reflection regarding the woman in the performance of the paper of "queen of the home" in Brazil of the beginning of the XX century. In the preparation of the house rested the valuation of a controlled behavior of the housewife, that would have to keep the control on everything and all, having there the chance to demonstrate its capacity to govern itself, its home and its family.
\end{abstract}

Key Words: Containment, Self-Guidance, Administration of the Home. 
O homem deve ter mais energia e mais cérebro; a mulher, mais habilidade e mais coração. Isabel Serrano - 1949

$\mathrm{O}$ Brasil do início do século $\mathrm{XX}$, em meio a um quadro econômico e político que alterava sensivelmente as relações sociais, vive um período marcado pela busca das elites por um conforto "civilizado" junto aos benefícios da modernidade e da sofisticação.

O processo de urbanização, iniciado no século XIX, e o desenvolvimento das cidades influenciaram a valorização da intimidade calcada na busca de um requinte do cotidiano, na idealização de um ambiente familiar feliz, acolhedor, repleto de filhos saudáveis e educados, mãe dedicada e marido responsável, características que representavam, segundo D'Incao (1997:223), um "tesouro social imprescindível".

Frente às mudanças, os conservadores procuraram criar um "verdadeiro culto da aparência exterior, com vistas a qualificar de antemão cada indivíduo". Essa nova estrutura terá como principal resultado a construção de uma vida privada ligada ao público, "repercutindo na organização do espaço doméstico, na decoração requintada dos ambientes e nas novas formas de convivialidade" (Schapochnik, 1998:440).

É estabelecido um modelo de família orientado para a intimidade do lar, onde devem ser praticadas todas as virtudes anteriormente aprendidas no processo de preparação para o casamento. Essa espécie de aparelhamento feminino dirigia-se, em especial, às mulheres das classes mais abastadas, das quais se exigia toda uma educação para a vida matrimonial.

Nesse sentido é que Margareth Rago (1997:62) fala na "promoção de um novo modelo de feminilidade, a esposa-donade-casa-mãe-de-família, e uma preocupação especial com a infância, percebida como riqueza em potencial da nação (...)".

Claudine Haroche (1998) em seus estudos sobre posições e precedências fornece dados para a compreensão da linguagem 
Labores, quitutes e panelas

dos gestos que possibilitam a comunicação social entre os homens. A análise da autora sobre os significados dos gestos, posturas, movimentos dos corpos individuais e coletivos permite entrever as relações de poder estabelecidas entre os membros de uma mesma família, em especial o poder da mulher no exercício de seu papel como dona-de-casa.

Haroche considera a contenção um componente essencial do poder e vê no governo de si fundamento necessário do governo dos outros. Dessa forma, atitudes e gestos descontrolados, representam posição de inferioridade, ao passo que o domínio sobre si representa uma posição de superioridade.

Conforme a autora, a moral ensina a maneira de governar a si mesmo, bem como a forma de administrar as finanças e a política, de acordo com as normas ditadas pela razão.

Logo, todo ser humano, pai de família ou soberano, deve saber se disciplinar, regrar a si mesmo, subtrair-se aos impulsos do sentimento e submeter-se às regras da razão. Saber conduzir uma família ou, em outras palavras, ser um bom ecônomo, e bem governar um povo provêm fundamentalmente de uma mesma exigência - fruto de longo aprendizado -, de um mesmo princípio, de uma mesma qualidade, saber governar a si mesmo (Id. ib.:40).

Como aponta Schapochnik (1998:501), para a sociedade brasileira da primeira metade do século XX:

Nas salas e salões, a recepção adquiria a função de veículo informal pela disputa de cargos e privilégios, na qual estreitavam-se alianças financeiras, tramavam-se candidaturas políticas, estimulavam-se intrigas entre concorrentes, estabeleciam-se compromissos matrimoniais.

Essa qualidade de governar a si mesmo aparece nos livros de cozinha e de administração do lar do período aqui analisado, pois, "quer se trate de economia doméstica ou de política, o 
governo de si é indispensável ao governo dos outros" (Haroche, 1998:40). Como prevê a autora de um dos livros de administração do lar, Isabel de Almeida Serrano (1949:30), "a esposa exerce grande influência quanto ao sucesso político e social do esposo". ${ }^{1}$

Porém, não somente a organização dos recintos sociais deve ser levada em conta, mas também a das esferas familiares, áreas estas que, ocasionalmente, são vislumbradas por visitantes, íntimos ou não. Numa sociedade em que as marcas de identidade e distinção evidenciavam-se nos mínimos detalhes, os objetos que compunham o arranjo dos espaços dos lares, a organização doméstica e a administração dos comportamentos eram requisitos fundamentais para o desempenho do papel de uma dona-de-casa ideal.

As fontes analisadas - manuais de administração do lar e livros de cozinha que circulavam no Brasil da virada do século XX até meados dos anos de 1960 - apresentam situações que evidenciam a valorização de uma conduta controlada da "rainha do lar", que como dona-da-casa, deveria manter o controle sobre tudo e sobre todos, demonstrando assim sua capacidade de governar a si, seu lar e sua família, apoiada pela figura do marido. Para o marido possuir um lar organizado era prova do governo dos outros como extensão do governo de si, podendo servir como indício de sua possível competência para a administração dos ambientes públicos, além dos domínios dos espaços da vida privada.

Nesse sentido, as mulheres casadas ganhavam a possibilidade de contribuir para o projeto familiar através de sua postura nos salóes e na vida cotidiana. Sua imagem deveria refletir o cuidado dos filhos e do marido, a supervisão dos criados,

1 Este título é um manual de organização doméstica, cuja autora, antes professora, passou, no período em que escreveu a obra, a realizar conferências e cursos sobre formação familiar e social. Munida da experiência de mãe e esposa, frente aos desafios do mundo e das notícias sobre a "desgraça" dos lares por falta de instrução das donas-de-casa, começou a se interessar pela educação em geral, dirigindo-se tanto aos lares modestos como os mais abastados. 
Labores, quitutes e panelas

e a boa condução da casa. Nesse sentido D'Incao (1997:229) vê a dona-de-casa como portadora de um "capital simbólico", ou seja, embora o chefe da família seja o homem, de certa forma, este ainda estava sujeito à imagem que suas mulheres deixavam mostrar as pessoas de seu convívio.

Sobre isso Vera Cleser, em O Lar Doméstico, aponta que os olhares dos estranhos começam pela arrumação do hall de entrada:

Os estranhos avaliam as qualidades domesticas duma dona de casa pela sua sala de entrada. Si na escada e na porta faltar o capacho e o aparelho para limpar os pés, si a escada fôr pouco asseiada, si, esparsos pelo chão, se vêem objetos diversos, não esperará encontrar uma dona de casa activa e ordeira (Cleser, 1906:113). ${ }^{2}$

Complementando estudos desenvolvidos anteriormente sobre as atitudes e partilha dos alimentos, neste artigo proponho uma reflexão sobre os preceitos em relação aos "bastidores" (cozinha e despensa) onde se preparam as iguarias - não no sentido da elaboração em si, mas sim nos objetos que a cercam. A partir disso procuro reconhecer as normas contidas nas fontes como formas implícitas ou explícitas de cultura e poder capazes de conferir a imagem do lar ideal sob a regência da "boa dona-decasa".

\footnotetext{
2 Manual de administração do lar traz de forma didática uma série de informações sobre a administração da casa. A obra é dividida em quatro partes. Na primeira, a autora contempla ensinamentos sobre a organização do que ela chama de "movimento diário" do lar, que, diz ela, deve ser guiado principalmente pela ordem. A segunda trata das partes da casa - salas, quartos, cozinha, despensa, utensílios de cozinha, quintal e jardim. A terceira é dedicada à preparação das iguarias e à arte de educar a criada. A última parte refere-se às "occupações especiais": a arte de comprar, normas referentes à limpeza de copos, pratos, xícaras, panelas e, ainda, sobre a "chimica domestica".
} 
Maria Cecília Pilla

\section{A cozinha ideal}

Dez pontos definem a cozinha ideal: disposição dos alimentos, boa iluminação, suficiente espaço de armazenagem, utensílios ao alcance da mão, bastantes tomadas elétricas, facilidade de limpeza, ventilação adequada, abundante suprimento de água, pias apropriadas e localização conveniente em relação à sala de jantar (Bom Apetite, 1968). ${ }^{3}$

Os manuais de administração do lar e os livros de cozinha examinados são unânimes em apresentar a cozinha como a principal parte da casa. É nela que se preparam as iguarias, uma tarefa quase sagrada da boa dona-de-casa, se não desempenha essa tarefa, pelo menos deve inspecionar e comandar de forma a produzir alimentos saudáveis para garantir uma vida melhor aos seus filhos e marido.

No período analisado reina o discurso médico que prega a vigilância $e$ a atenção da mulher em sua função de dona-de-casa. Responsável pelo bem-estar em seu lar, ela deve zelar pela saúde de seu marido $e$ filhos e todas as outras pessoas que vivem sob seu teto. Segundo os higienistas da época, cuidar do lar é justamente, preocupar-se com a higiene e a limpeza, na luta incessante contra germes, poeira, lixo, tudo aquilo que pode vir a macular a imagem do lar ideal.

Cleser prevê um cuidado especial na construção $e$ decoração da cozinha. As paredes devem ser azulejadas e o chão de ladrilhos. Segundo ela é preciso pensar sobre como decorá-la levando-se em conta principalmente o quesito limpeza: "As paredes e o tecto da cozinha de uma casa bem dirigida não devem nunca chegar a estar sujos" (Cleser, 1906:164). O fogão precisa ser de tamanho proporcional ao tamanho da família e também deve estar sempre limpo com seus "metaes

3 Esta enciclopédia diz ter por objetivo "desvendar" para a leitora os saborosos segredos da cozinha de todo o mundo. 
Labores, quitutes e panelas

escrupulosamente areados e brunidos" (Id. ib.:166). Os cuidados se estendem à pia, às prateleiras, aos panos diversos para lavar $e$ enxugar a louça e, quando a cozinha comportar, deve ter ao centro uma mesa quadrada de "pinho alvíssimo para a louça lavada e enxaguada".

Os conselhos são seguidos por um alerta sobre os cuidados com a limpeza e se estende aos utensílios da cozinha. Ao apresentar uma novidade norte-americana - "panellas de vidro inquebrantável" -, chama a atenção a propaganda centrada na substituição das panelas de metal, porque justamente facilitam $e$ asseguram uma maior limpeza. É "asseiadissimo e resiste á bruscas mudanças de temperatura, vantagem sobre as panellas de ferro". Superam as de ágata, que apesar de garantirem tanta higiene como as novas de vidro, não têm tanta resistência e, segundo ela, "tornam-se muito caras para a cozinha economica" (Id. ib.:171-174).

A ênfase nos cuidados com o asseio arremata seus conselhos advertindo sobre a responsabilidade da dona-de-casa pelo bom andamento desse setor de sua casa dizendo que: "O bem-estar physico depende em grande parte do asseio dos utensílios da cozinha; della sae a saúde ou o soffrimento e até mesmo a morte" (Id. ib.:175).

A inquietação provocada pela limpeza está relacionada aos paradigmas da civilização. Considerada verdadeira virtude doméstica ela é esperada de todos, independentemente da condição social. Para Cleser, uma "bôa dona de casa estará sempre asseiada e arranjanda e nunca terá de receiar o olhar de estranhos". Mesmo as casas mais humildes devem ser "asseiadas; é justamente nellas que o asseio suppre o luxo". Na cozinha ideal nunca deve faltar o necessário para se fazer a higiene, e é responsabilidade da dona-de-casa inspecionar "rigorosamente a sua cozinha", pois coisas que podem parecer "insignificantes da vida domestica podem ter as mais repulsivas consequencias. $\mathrm{O}$ olhar perscrutador da dona de casa, eis o que nunca deve faltar" (Id. ib.:25-32). 
Para Isabel Serrano (1949:157) é dever da dona-de-casa dispensar cuidados especiais à limpeza da cozinha. Seu bom gosto deve se estende a essa peça garantindo sua mais escrupulosa limpeza.

Perpétua de Lemos (1954:15) nos "anos dourados" faz sugestões de como tornar uma cozinha eficiente, interessante e bonita. Para ela, a cozinha é o

laboratório onde se preparam os alimentos, portanto é a parte da casa mais diretamente à nossa saúde. E pelo seu arranjo, pela sua apresentação que, em geral, podemos conhecer as qualidades de uma mulher como dona de casa.

Permanecendo a preocupação com a limpeza, seu controle $e$ encargo continuam relacionados às responsabilidades da donade-casa, sob pena de revelar-se como a antítese do modelo dela esperado - desleixada e desordeira.

A autora reconhece na cozinha dos anos 1950 recursos e aparelhagem que propiciam mais higiene e conforto, praticidade e eficiência do que as "de antigamente". Quando tomamos um manual como o Lar Doméstico, de 1906, devemos levar em conta que pouco se falava em fogão a gás, tampouco se pensava em refrigerador. Uma das maiores novidades da época, anteriormente citada, eram as "panellas de vidro inquebrantavel".

Portanto, a funcionalidade vai aparecendo, paulatinamente, assim como a diversificação e acesso a eletrodomésticos. Cleser já fala em poupar tempo como um elemento diretamente relacionado à questão da ordem, ao que se poderia identificar como uma organização do tempo. Para ela, uma dona-de-casa que saiba dividir bem os trabalhos domésticos,

póde, mesmo em posição modesta, ter a sua casa em estricta ordem e sobra-lhe-á tempo para exercer uma occupação profissional com que augmente as suas rendas. Onde as circumstancias não exigem isto poderá lêr um bom 
Labores, quitutes e panelas

livro ou continuar e aperfeiçoar a sua instrucção (Cleser, 1906:6).

Perpétua de Lemos e outros autores de sua época se preocupam com a funcionalidade da cozinha, porém muito mais com sua decoração e seu equipamento como facilitadores do trabalho feminino no lar.

A chamadas "cozinhas modernas" devem ter duas finalidades: preparar os alimentos e lavar e guardar pratos $e$ panelas. Sua funcionalidade deve propiciar que tudo fique à mão, por isso é preciso que sejam pequenas para que tenham o máximo de eficiência num mínimo de tempo. Semelhante a essa percepção, Íside Bonini (1963) diz que a cozinha permanece como a peça mais importante para o lar, apesar de ter deixado de ser o ponto de reunião familiar íntima para tomar ares exclusivamente funcionais.

A autora ressalta a questão do asseio e do conforto que, juntamente com os equipamentos devem criar um todo harmonioso - móveis, paredes, revestimentos, tudo que facilite a limpeza. E arremata que o cuidado com esses aposentos, bem como o controle sobre o inventário de seus objetos, constitui o orgulho da dona-de-casa, pois:

a administração da casa compete à mulher. $\mathrm{O}$ bom andamento administrativo é fator de ordem e de economia ao qual a boa dona de casa deve dedicar algumas horas diariamente (Id. ib.:32).

Técnicas e habilidades na cozinha são competências que Aleta Crawford (1966:22) espera das donas-de-casa nos anos 1960. Para ela, "a qualidade do trabalho na cozinha é determinada mais 
pelo capricho ou grau de excelência exigido pela dona-de-casa do que pelo equipamento". 4

A ordem é inseparável da limpeza, sendo também termômetro para medir a capacidade e qualidade da dona-decasa. Como aponta Cleser (1906:4),

um espirito de ordem deve dar aos trabalhos caseiros da mulher um valor mais elevado e ser a senda sobre a qual se mova tranquillamente este pequeno reino em que ella é soberana. [E completa] nada tem sobre nós uma influencia tão poderosa, nada embelleza tanto a nossa vida domestica, augmenta nosso bem-estar e poupa nosso tempo como a ordem.

Ao relacionar a ordem à limpeza Cleser, de forma direta, adverte:

uma dona de casa activa não deixa a desordem introduzirse no seu lar; exige rigorosa limpeza em tudo, não tolera nodoas de gordura no chão da cosinha, muito menos ainda nos outros commodos, nos moveis, na roupa e nas paredes. A sua propria pessoa deve ser um exemplo vivo de ordem, asseio e simplicidade (Id. ib.:6).

Em Minha Casa, Isabel Serrano valoriza a ordem e a arrumação da casa, no entanto, não considera esta tarefa nada fácil e aconselha que, logo nos primeiros anos de casamento se disponha tudo da melhor maneira possível, pois, para ela, conservar a ordem facilita os trabalhos da casa.

A tarefa da dona de casa será facilitada, a perfeição do serviço, a calma e o sossego do lar estarão garantidos, se cada objeto tiver o seu lugar determinado, se tudo for feito

\footnotetext{
4 A autora pretende com este livro fornecer técnicas sobre a ciência de preparar alimentos e dirige-se, de forma especial, àqueles que se interessam pelas ciências domésticas, podendo, segundo a autora, ser bastante útil às donas-de-casa.
} 
Labores, quitutes e panelas

à hora certa e no dia em que deva ser feito, pois acumular trabalhos é aumenta-los e tornar a sua execução imperfeita $e$ fatigante. É dispêndio inútil de energia que, bem aproveitada, operaria prodígios. A ordem é a base da prosperidade, e a disciplina é a base da ordem (Serrano, 1949:142).

A citação evidencia a importância em cultivar a virtude do autocontrole; a plena administração da casa está nas pequenas coisas e tudo deve estar sob o governo da dona-de-casa. A autora ressalta, ainda, que a desordem da casa é uma das maiores causas das desavenças do lar podendo refletir na atuação profissional do marido. No entanto, adverte que o método e a ordem devem ser cultivados tanto pelo homem quanto pela mulher:

a casa bem arrumada produz a impressão de aconchego $e$ de paz. Não pode existir verdadeira paz interior nos moradores de uma casa completamente desorganizada. $\mathrm{O}$ exterior é o reflexo do interior. Um homem que tem os seus documentos em desordem, certamente também assim terá os seus negócios (Id. ib.:143).

Assim aconselha: "todas as coisas no seu lugar e para coisa o seu lugar certo". Perpétua de Lemos (1954:23) de forma didática aponta as "normas para manter uma cozinha sempre em ordem":

Não acumule coisas desnecessárias.

1. Tenha, exclusivamente, a aparelhagem que lhe é imprescindivel. Desta forma, os utensílios estarão sempre em uso e não ficarão empoeirados.

2. As prateleiras devem ser arrumadas de maneira que cada objeto tenha o seu lugar próprio e fique sempre próximo do lugar em que é mais utilizado e à mão da pessoa que trabalha.

3. Use ganchos nas prateleiras para neles pendurar os apetrechos de cozinha que estão constantemente em uso, como medidas, escumadeira, concha, colher de pau, etc. 
Maria Cecília Pilla

\section{Despensa}

Peça anexa à cozinha a despensa é considerada necessária para seu melhor funcionamento e conservação dos alimentos. Para Cleser (1906:163), no início do século XX, "em nenhuma casa deve faltar uma despensa bem ventilada", com paredes limpas, janelas com telas, chão cimentado ou ladrilhado e deve conter ainda prateleiras, guarda-comida, balança, caixa com divisões para especiarias, ganchos para toucinho, carne seca, redes de cebolas e alho, saquinho de linho-branco para pão, cestas para o mercado e açougue.

É na despensa que se guardam as provisões que a autora considera indispensáveis: banha, manteiga, toucinho, massas, sal, pimenta em grão, açúcar, chá, café, vinagre, batatas, azeite fino, ovos, leite, sabão, querosene, velas e fósforos. Nos anos seguintes, muitos desses produtos serão guardados na geladeira, mas nesse período eram conservados na despensa, e deviam ser inspecionados, e seus usos controlados, pela dona-de-casa. Cleser aconselha inclusive que essa peça seja trancada e suas chaves fiquem em posse da dona-da-casa ou da criada de maior confiança. E finaliza: "Uma despensa limpa e arrumada denota uma dona de casa bem educada, activa e ordeira" (Id. ib.:163).

Outros manuais de administração doméstica mais recentes também se dedicam à despensa, mas não lhe reservam um capítulo distinto. Lemos (1954:163) se refere à despensa moderna como aquela que deve conter armários embutidos onde se armazenam os mantimentos. Pela ilustração do livro parece se confundir com um grande armário que acompanha a cozinha. Somente para casas de maior porte prevê uma dispensa anexa, grande o suficiente para, além dos mantimentos, comportar uma geladeira, onde se guardam os alimentos facilmente afetados pelo calor.

Como Lemos, Irene Albuquerque (1951:118), no mesmo período, indica que a "dispensa pode constituir-se numa peça da 
Labores, quitutes e panelas

casa, mas pode se limitar a um armário ou a uma armação com prateleiras". ${ }^{5}$

\section{Considerações finais}

Conforme Haroche (1998), a moral ensina a maneira de governar a si mesmo, bem como, no caso deste artigo, a forma de administrar o lar a partir de normas ditadas pela "razão". Saber conduzir a família é importante para seu auto-governo. No entanto, é preciso ressaltar que essa qualidade pode e deve ser cuidadosamente aprendida. Isso é o que preconizam os manuais de administração do lar e livros de cozinha, pois as donas-de-casa, mesmo as mais experientes podem recorrer a ele em caso de dúvida. Quanto às novatas, às jovens noivas ou recém casadas, os manuais podem ensinar a construção de seu novo lar.

Dessa forma este estudo reflete, em especial sobre a preparação da casa como elemento de valorização de uma conduta controlada da dona-de-casa, que deveria manter o governo sobre tudo e sobre todos, uma oportunidade de demonstrar sua capacidade de governar a si, seu lar e sua família. Assim, de forma particular, o controle da administração dos chamados espaços de serviço (cozinha, despensa) e sua relação com os lugares de sociabilidade (salas de estar e jantar) marca positivamente o lugar das mulheres nesses espaços.

Assim como se esperava que o homem - chefe da casa cuidasse financeiramente de seus dependentes, considerava-se verdadeiramente "vãos, insufficientes, inuteis mesmo, si a dona de casa ignorar ou desprezar a grande sciencia da economia e dos trabalhos domésticos" (Cleser, 1906:3).

\footnotetext{
5 Manual de administração do lar elaborado de forma didática, pois, além de trazer os preceitos para o bom andamento de uma casa, ao final de cada capítulo são encontradas questões para reflexão sobre os assuntos abordados.
} 
Maria Cecília Pilla

\section{Referências bibliográficas}

AlbuQUeRQue, Irene. Noções de economia doméstica: liuro de interêsse permanente para a mulher brasileira. $5^{\mathrm{a}}$ ed. Rio de Janeiro, Conquista, 1951.

Bonini, Íside. Boas maneiras: em sociedade. São Paulo, Edigraf, 1963.

Cleser, Vera. O lar domestico. conselhos para boa direcção de uma casa. Rio de Janeiro, Laemmert \& C., 1906.

Crawford, Aleta Mc Dowel. Alimentos: seleção e preparo. São Paulo, Record, 1966.

D'InCAO, Maria Ângela. Mulher e família burguesa. In: DEL PRIORE, Mary. (org.) História das mulheres no Brasil. São Paulo, Contexto, 1997.

HAROCHE, Claudine. Da palaura ao gesto. Campinas-SP, Papirus, 1998.

LEMOS, Perpétua. Enciclopédia de Arte Culinária. Rio de Janeiro, Globo, 1954.

RAGO, Margareth. Do cabaré ao lar: a utopia da cidade disciplinar. Brasil 1890-1930. $3^{a}$ ed. Rio de Janeiro, Paz e Terra, 1997.

SCHAPOCHNIK, Nelson. Cartões Postais, álbuns de família e ícones da intimidade. In: NovAIS, Fernando. (org.) História da Vida Privada no Brasil. Vol. 3, São Paulo, Cia das Letras, 1998.

SERRANO, Isabel de Almeida. Minha casa. Rio de Janeiro, Vozes, 1949.

\section{Revista}

Bom Apetite, vol. 2, São Paulo, Editora Abril, 1968. 